University of Louisville

ThinkIR: The University of Louisville's Institutional Repository

College of Arts \& Sciences Senior Honors

Theses

College of Arts \& Sciences

$5-2015$

\title{
The consequences for children of incarcerated parents.
}

Lashawn Ford

University of Louisville

Follow this and additional works at: https://ir.library.louisville.edu/honors

Part of the Criminology Commons, and the Social Welfare Commons

\section{Recommended Citation}

Ford, Lashawn, "The consequences for children of incarcerated parents." (2015). College of Arts \& Sciences Senior Honors Theses. Paper 59.

http://doi.org/10.18297/honors/59

This Senior Honors Thesis is brought to you for free and open access by the College of Arts \& Sciences at ThinkIR: The University of Louisville's Institutional Repository. It has been accepted for inclusion in College of Arts \& Sciences Senior Honors Theses by an authorized administrator of ThinkIR: The University of Louisville's Institutional Repository. This title appears here courtesy of the author, who has retained all other copyrights. For more information, please contact thinkir@louisville.edu. 
The Consequences for Children of Incarcerated Parents

By

Lashawn Ford

Submitted in fulfillment of the requirements for Graduation summa cum laude

And

For Graduation with Honors from the Department of Justice Administration

University of Louisville

May 2015 


\section{INTRODUCTION}

Mary is a young girl, originally from Chicago, Illinois. She lives in Kentucky with her mom, brother, and sister. Her mom and biological father separated when Mary was five. Although Mary’s biological parents are separated, she maintains a close relationship with both. When Mary was eleven years of age, her biological father was sentenced to fourteen years in prison. No one explained the dynamics of her father's incarceration. It was a lot to handle for an eleven year old girl. Before the incarceration, her father lived in Chicago, Illinois. Although they did not live in close proximity to each other, Mary and her father had a close relationship. They spoke over the phone multiple times a week and saw each other roughly once a month. However, the incarceration of Mary’s father changed everything. They went from consistent communication prior to incarceration to a phone call, maybe once a month, during incarceration. In addition, Mary’s circumstances changed. For example, the family struggled more financially; Mary and her brother struggled academically; and Mary became more aggressive. Seven to eight years later, Mary’s father was released from prison, but the connection Mary and her father had prior to his incarceration had been lost.

This description of events is played out thousands of times, annually, across the United States. The children of incarcerated parents become "collateral damage" of the conviction and incarceration process. The purpose of this paper is to address the following questions concerning the consequences for children of incarcerated parents:

1. How prevalent is this problem in the United States?

2. What are some of the short and long-term consequences for children and society when parents are incarcerated? 
3. Is there anything agencies like the criminal justice system could have done to reduce the consequences of parental incarceration for Mary?

4. What can be done to help maintain the parent-child bond during incarceration?

There have been many controversies within the United States regarding the criminal justice system. One of the most common notions is the lack of support we give to the victims of crime. Generally, we associate the term "victim" with individuals who are directly harmed by the crime; however, we rarely consider the families of incarcerated offenders as victims (Light and Campbell 306). According to the U.S. Department of Justice, over fifty percent of state and federal inmates have at least one child under eighteen years of age (Glaze and Maruschak 1). This paper will focus on the effects incarceration can have on the families of the incarcerated individual, specifically the children. The effects of parental incarceration will be examined along with the effectiveness of existing strategies and programs designed to reduce the effects of parental incarceration. Lastly, a proposed pilot program, based on existing literature on this topic, will be examined as a means to minimize the consequences of parental incarceration on children.

\section{CONSEQUENCES OF INCARCERATION}

In 2007, it was estimated that of the 1,518,535 inmates held in prisons in the United States, 809,800 had children under the age of eighteen (Glaze and Maruschak 1). This is over fifty percent of inmates. Parental involvement is important for a child's development and has shown to be an important determinant in factors such as academic achievement and self-efficacy (Choi 159). If parents are inmates, children may lack the guidance and support needed for positive child development. Often, children follow in the same path as their parents, not 
necessarily a direct path, but broadly speaking. For example, if a child's parent went to college then it is likely the child will go to college. This same notion applies to children with incarcerated parents. In fact, studies have shown children with incarcerated parents are six times more likely to be a criminal adult offender in comparison to children without incarcerated parents (Crain 65). This cycle of parent and child criminality, also known as the cycle of intergenerational incarceration, may be one of the most well-known negative effects of parental incarceration (Crain 65).

Children and adolescents are more impulsive than adults. Typically, after adolescence we experience cognitive, emotional, and social maturation and learn how to control these impulsive behaviors (Steinberg 10). However, when children and adolescents of incarcerated parents are experiencing constant change (e.g., loss of parent, financial instability, and depression) and these changes are mixed with their impulsive nature, this will likely increase the chances of them offending. Once these youth become juvenile offenders there are stigmas/labels placed on them, and these stigmas are difficult to eliminate from their character (Sander 322). Stigmatization is when a person or group, such as offenders, is discredited because of their status. For example, if a burglary crime occurs in a neighborhood, there is likely to be the assumption that the youth with the juvenile record committed the crime, whether he/she did it or not. Eventually, if the stigma continues to be reinforced (e.g., by the people in the neighborhood) then the youth will start to internalize the stigma. That is, the youth may begin committing these crimes because it is already expected of him/her. This internalization and externalization of the crime is called the self-fulfilling prophecy (Madon 578). 


\section{Stigmatization}

Parental incarceration does not guarantee the child will become an offender. However, this notion of stigmatization extends beyond the actions of the youth. There is a large body of research on how stigmatization affects people with criminal and juvenile records. However, there is not much research on how parental incarceration itself can be stigmatizing to the child. A parent being incarcerated is not something families, specifically children, want to announce to others. Children are perceived differently when they have incarcerated parents. As previously mentioned, it is common to think of children as following in their parents' footsteps. If this is the case, the children who have incarcerated parents are more likely to be labeled as deviants and criminals, whether they have committed a crime or not. It may appear that the best way for children to avoid this stigmatization is to conceal the fact that they have incarcerated parents. Having to conceal this information from other people can be stressful and some children may experience a sense of detachment from themselves and others. In fact, studies have shown the relationship between parental incarceration and children's well-being is significant, in that children with incarcerated parents experience an increase in mental, emotional, and social problems (Turney 303). It is important for these children to find support when they feel stressed, but stigmatization may limit them from opening up and reaching out for much needed social support.

\section{Diminished Bonds with Parents}

The parent-child bond is a crucial factor in determining adjustment of the child once the parent is incarcerated (K. Miller 475-76). Ensuring the strength of this bond can make a significant difference in the social, psychological, and emotional issues the child will face. Consistent communication is one way the bond between parent and child can remain intact 
during incarceration. However, when a parent is incarcerated consistent communication becomes difficult. The cost of communication for families can be overwhelming when these costs include phone calls and transportation for visitation (e.g., gas and food). The more families communicate with the incarcerated parent the higher the financial cost will be. It is common for families and incarcerated individuals to be separated by a large distance. Studies have shown that in 2004 nearly half of inmates lived 100-500 miles away from their families (Schirmers, Nellis, and Mauer 8). This distance can be an issue because of the financial cost and the large amount of time it would take for the families to travel and visit the incarcerated parent. Furthermore, although inmates are provided the basic necessities in prison, there are times when they need money to pay for miscellaneous items (e.g., snacks), and their families may be the only ones willing to contribute to these needs. Therefore, the culmination of all of these expenses can take a toll on a family's socioeconomic status_-we will return to this topic in a moment.

There is a difference between the quality and the quantity of visitations between parent and child. Previous studies have shown that when offenders have better quality visitations, the relationship between the parent and child seemed to be stronger than when they have high quantity visitations (Beckmeyer \& Arditti 144). A good quality visitation would mean the parent and child have a feeling of closeness. This closeness does not necessarily mean the parent-child had a positive or pleasant visitation. The visitation could have been argumentative. The important thing is for both parent and child to be able to express their feelings with one another. Although quality visitation is of higher importance, this does not mean frequent visitations are not important for the parent-child relationship. If children only communicate with their parent(s) once a month it will be difficult to have a good quality relationship. Therefore, the combination 
of both quantity and quality visitations should be emphasized in the process of reducing the consequences of parental incarceration.

Finally, why should we care? What does ensuring parents and children have a good quality relationship do for society? For one, as mentioned above, adult criminality is one consequence that is positively correlated with children that have incarcerated parents. However, when parent and child have a good quality relationship this cycle of intergenerational incarceration can be broken. Parents' involvement is significant in the social functioning of children, especially younger children (El Nokali, Bachman, and Votruba-Drzal 989). So, if the cycle of intergeneration incarceration is going to be broken, maintaining the bond between parent and child is crucial. Also, a strong parent-child bond does not only reduce the chances of offending for the youth, but studies have also shown that there is a reduction in recidivism rates or re-offending for the inmate (i.e., the incarcerated parent) (Makariev and Shaver 324).

If we can prevent re-offending by the parent and potential offending of the child, we could reduce the amount of money we put into the criminal justice system. In 2010, the lowest average annual cost per inmate was in Indiana and was estimated to be $\$ 14,000$. The highest average annual cost per inmate was in New York and was estimated to be $\$ 60,000$. The national average was roughly $\$ 30,000$ (Henrichson \& Delaney 10). The United States incarcerates more people than any other country (Chang 1-2). In 2013, the number of prisoners in the United States reached a staggering 1,574,700 (Carson 1). The amount of money the justice system spends solely on inmates should be alarming. Interestingly, the countries with the lowest incarceration rates seem to be more collectivistic cultures, meaning they place more value on the group's interests and family togetherness. If policies and initiatives to maintain family bonds during 
periods of individual incarceration in the United States were more widespread, it is feasible that this would reduce the incarceration rates.

\section{CONTRIBUTING FACTORS}

One social circumstance of the family that contributes to the various effects on the child is the pre-existing relationship between the family and incarcerated individual. Stronger bonds between parent and child prior to incarceration are going to be more crucial in maintaining the relationship compared to if the parent-child bond was weak prior to incarceration (Miller 475476). Basically, a child who rarely or infrequently communicated with his/her parent prior to incarceration is not going to be affected as much as the child that consistently communicated with his/her parent prior to incarceration. Although some children have unsatisfactory relationships with their parents prior to incarceration, they do not necessarily have to continue their unsatisfactory relationship. That is, this relationship can become stronger during the parent's incarceration. In addition to the pre-existing relationship, it is important to factor in the length of the parent's incarceration because this could limit or expand the financial, psychological, social, and emotional consequences of the child. If a parent is only incarcerated for a short period of time (e.g., less than a year) then it is likely there would be fewer effects on the child, parent, and their relationship in comparison to a case where the parent is incarcerated for many years.

Also, the caregiver relationship plays an important role in the effects parental incarceration has on children and the relationship between the incarcerated parent and child (Young 130). Research has shown roughly half of inmates lived with their children prior to their incarceration (Parke \& Clarke-Stewart 2). Since half of children lived with their incarcerated 
parent, the other half lived with a caregiver, meaning the caregiver is involved in the child's life just as much as the incarcerated parent. The caregiver of the child can include a parent, grandparent, cousin, foster parent, or anyone who is designated to be the guardian of the child. This person should help the child adjust to their parent being incarcerated; understand the parent's incarceration; and assist in maintaining the relationship between parent and child. Some studies have found, caregivers sometimes have conflicting views regarding the child's visitation with the incarcerated parent because of the emotional pain it can produce (Arditi 116-8). Caregivers are the individuals responsible for taking the child to visit their incarcerated parent. The caregiver's attitude towards the parent and/or visitation of the parent can create barriers on the parent-child relationship (Arditti 122-5). The caregiver may feel that he/she is protecting the child, but from the research it seems maintaining this bond between parent-child will do more good than harm.

\section{Social Class}

When a parent is incarcerated, communication between parent and child is severely hindered. These effects may vary depending on the social circumstances of the family. In 2002, the majority of inmates in prison were classified as either lower social class or homeless (James 9). These conditions may only exacerbate the consequences of parental incarceration for children. Families with lower incomes have fewer resources to support the incarcerated parent and may have a difficult time maintaining consistent communication by phone calls and visitations because of the financial cost. Therefore, it is likely that these families are more negatively affected by parental incarceration when compared to families in the higher socioeconomic categories. 
Once a family member is incarcerated, there is an increased chance that the family's financial situation will change (Christian 2-4). This change is mainly due to the loss of an economic provider. In today's economy, it often takes more than one person working in the household to have financial stability. One option to make up the financial loss of the incarcerated parent is for the non-incarcerated parent to work more hours. However, if one parent is incarcerated and another parent is constantly working this is equivalent to the child losing both parents which may lead to problems of child development.

It is important for children and adolescents to have guidance. Many studies have shown parental monitoring is beneficial for child development such as academic achievement, selfregulation, and substance use outcomes (Farlee 23). Unfortunately, if one parent is incarcerated and another parent is constantly working, these children may lack sufficient parental supervision. Families in lower social class may have a difficult time monitoring the youth due to their job restraints. Typically, lower wage jobs are more time-consuming and lack flexibility (Dodson \& Albelda 9-12). This can put the caregiver in a difficult position because it may feel like they are choosing between providing the basic necessities for the child (e.g., food, water, and shelter) rather than monitoring the child in order to prevent risky behavior and enhance the child's development. However, when caregivers are unable to provide children with the supervision they need other agencies such as community and educational institutions should become a safety net.

\section{Education}

Education is known to be the great equalizer. That is, having a higher education can make a significant difference in social mobility (Haveman 125). Inmates are less likely to have a high school diploma and/or college degree compared to the national average; in fact, studies show roughly forty percent of inmates in 2003 had less than a high school education (Educational 
Attainment, Employment and Incarceration 1). The relationship between parental education and children's educational attainment has been shown in a variety of different studies, and include a number of contributing factors that can reduce or enhance the chance of children following in a similar path as their parents. For example, children that live in low socioeconomic neighborhoods are more likely to attend underperforming schools. These schools typically do not provide the best quality education or quality teachers that are going to help these children succeed (Morgan 292-3).

Since children of incarcerated parents are typically in the lower socioeconomic class, whether before or after incarceration, they also will be limited in support and opportunities for better education. Educational policies, such as No Child Left Behind (NCLB), were put in place to combat the issues faced by these disadvantaged children (e.g., children with incarcerated parents). However, the result of the NCLB act has portrayed an opposite effect. That is, this policy benefits a large amount of advantaged students over disadvantaged students (Wun 46872). The No Child Left behind Act required schools to meet certain testing requirements in order to get funding. This policy was supposed to hold the faculty and administrators accountable for the school's success or failure (The Elementary and Secondary Education Act (ESEA)). The schools that did not meet the testing requirements did not receive the funding. The problem with the testing requirements are the children that were considered to be disadvantaged went to the under-performing schools prior to the NCLB, and trying to force the underperforming schools to improve their test scores does not solve the root of the problem of why the test scores were low to begin with. Therefore, the chances of the underperforming schools' test scores improving or meeting the requirements of the NCLB act was highly unlikely compared to the schools that had high test scores prior to the NCLB act. 


\section{Psychological}

Some of the psychological aspects of parental incarceration can be the result of stigmatization. Stigmatization can invoke stress and sense of detachment (Domer 34). However, the psychological effects of parental incarceration go beyond these reactions. Naturally, a strong bond is formed between parent and child, and breaking that bond due to incarceration leads to emotional and psychological problems for both the parent and child. Studies have shown children with incarcerated parents show higher levels of depression and aggression and lower levels of self-esteem (La Vigne, Davies, and Brazzell 9). The children who are experiencing parental incarceration demonstrate internalizing (e.g., depression) and externalizing behaviors (aggression). Why are these psychological and emotional effects expressed after the parent is incarcerated? One reason may be because once the parent is incarcerated, children's lifestyles often change drastically, including, but not limited to familial instability, poverty, and lack of supervision and support. The combination of these factors and more can be overbearing on anyone, especially a child.

\section{Previous solutions, programs}

There are many programs and solutions that have been implemented to reduce the effects of parental incarceration. Many of these programs have shown promising results; however, they are not widespread and do not always tackle a wide range of effects. For example, one program is called the Girl Scout Beyond Bars (GSBB) whose main focus is keeping the connection between incarcerated mothers and daughters. This program is shown to have significant effects on enhancing the mother-daughter relationship by allowing them to have "frequent visits, decrease the tension of separation due to the incarceration, and reduce anxiety of postincarceration reunification” (Miller 479-80). The visitation between mother and daughter occurs 
monthly or bi-monthly for roughly two hours. During the visitation, the parent and child discuss important life issues such as teenage pregnancy, substance abuse, relationships, and coping with family crises. The girls get to gain life skills while maintaining a relationship with their mothers. The GSBB program provides transportation for the girls to go see their mothers in prison, no matter the distance, and the girls of the program partake in monthly meetings so they can connect with other girls in similar situations. According to the National Evaluation done by Girl Scout USA, eighty-four percent of participants in the GSBB program agreed that their relationship with their mother was better because of the program (Girl Scout Beyond Bars). In addition, the results of this program have shown to help the girls with emotional and social problems such as an increase in self-esteem, decrease in delinquency, and lower depression rates (Girl Scout Beyond Bars).

Although the GSBB has shown promising results, there are some important aspects of the program that are lacking. First, it does not include the caregiver, who is the guardian of the child during the mother's incarceration. The relationships between caregiver-child and caregiverparent have a huge effect on the development of the child (Parke \& Clarke-Stewart 7-8). Caregivers are vital in the parent and child relationship and must be included in the solution of the program. Secondly, although the program mentions providing transportation for visitation, it does not discuss providing other forms of basic communication such as phone calls and letters which are more frequent forms of prison communication. In-person visitation is the least frequent form of contact (Loper 56). The lack of frequent visitation would make it more difficult for parent-child to maintain a healthy bond. The GSBB program should provide girls with the resources to write a letter and/or talk to their mothers over the phone. Finally, although the program is intended for mother-daughters, the fact that boys and fathers are excluded from the 
program is an issue in itself. Women are significantly less likely to go to prison than men (Doris 2). Therefore, the GSBB program is only focusing on a smaller portion of a major issue of incarceration.

The next program called the Living Interactive Family Education (LIFE) takes a broader approach by dealing with the father and his children (boys and/or girls). This program focuses on improving parenting skills for fathers (i.e., the inmate). Similar to the Girl Scouts Beyond Bars Program, this program tries to enhance the relationship between the incarcerated father and child with interactive visitations and parenting training. These are monthly visitations. During these visits, the father and child participate in 4-H activities such as arts and crafts, and they discuss life issues/skills that include, but are not limited to substance abuse, conflict resolution, teamwork, and character development (Missouri 4-H Life 3-4). In addition, when fathers participate in the LIFE program they are required to participate in parent training sessions. This component helps fathers become a positive influence on their children. The parenting classes include, but are not limited to teamwork, communication, anger management, and positive discipline. The fathers are expected to apply the skills that they learn in the parenting sessions during the monthly interactions they have with their child.

Furthermore, the objective of the LIFE program is "to promote a strong, healthy, and nurturing family environment for children of incarcerated parents, while helping incarcerated parents become positive role models and mentors” (Missouri 4-H Life 4-5). Unlike the Girl Scouts Beyond Bars program, the LIFE program focuses more on the parent as a means to maintain the parent-child relationship. Parenting classes are important for building a strong parent-child relationship. However, a better or more effective program would have a higher focus on the child's well-being; for example, making sure the child has some sort of support 
system while their father is incarcerated such as community and/or caregiver support. Also, inperson visitation should not be the only form of communication between parent and child.

Another program called Motherly Intercession Organization runs intervention programs that are located in poverty stricken areas. The main goal is to keep mothers connected with their children by providing visitation and support to the families. There are two components to the program: Strengthening Families Program (SFP) and Parenting While Incarcerated (PWI). The SFP is a 16-week program targeted towards promoting social growth with family support and building strong bonds with the caregiver and child. This component offers many resources including, but not limited to tutoring for children, parenting/training classes for the caregivers, financial support for the families, and transportation to visit the mother. The PWI is an 8-week parenting class held in prison for the mothers. The purpose of the classes is to enrich the lives of the child (Miller \& Cochran). For example, the parent may have a training session focused on expectations of the child; substance and drug abuse awareness; effective discipline; and limit setting. The caregiver's training session would be similar to the parent's. When the parent and caregiver encounter the child, they are expected to use the skills that they learn. The results of this program "found that families who participated in the program reported improved family communication and organization; caregivers reported using positive parenting strategies more frequently, and also reported fewer depression symptoms, after participating in the intervention” (Miller \& Cochran).

One of the most significant components of the Motherly Intercession Organization is the inclusion of the caregiver. Caregivers become overburdened and lack resources once a parent is incarcerated, so it is important for them to get support. The main downfall to this program is it does not seem to last long enough. The entire program does not have to last the extended period 
of the mother's sentence, such as the direct financial support, but in order to maintain the parentchild relationship the visitation component should last the extended time of the mother's sentence.

The programs listed above all focus on maintaining and enhancing the parent-child bond during incarceration. Children can partake in other community programs designed to provide social support and guidance for their optimal success such as the Boys and Girls Club of America, Big Brother/Big Sister Program, and Girl Scout/Boys Scout programs. These programs can help with Positive Youth Development. Positive Youth Development examines the ability for the child to develop a healthy life. This method provides a foundation that will allow youth to make the right decisions in their life by focusing on education and community involvement (Travis 93-4). The community organizations become a protective factor for youth, especially children in adverse situations. Protective factors are conditions or coping strategies that protect against certain risk factors such as parental incarceration, financial instability, and a lack of parental monitoring. Involving children with incarcerated parents in these programs can possibly combat potential emotional and social problems.

\section{PILOT PROGRAM}

Based on the prior research, this section will describe a recommended program to be located at a medium security level institution, meaning the inmates are located in a secure facility throughout the day and are directly supervised by correctional officers, but these inmates are able to participate in self-improvement program, unlike inmates in a maximum security institution (Assigning Inmates to Prison). The primary purpose of the program will be to reduce the effects of parental incarceration and will include the major parties affected (i.e., the child, parent, and caregivers) and maintain the parent-child relationship during and after incarceration. As 
mentioned previously, there are many programs throughout the nation designed to reduce the effects of parental incarceration, but although these programs show positive results, they are not sufficiently comprehensive. The proposed pilot program would combine many aspects of the previously described programs with additional components that will create an expanded approach to reduce the effects of parental incarceration.

To start, quality of staff for the program is important. The program will have staff members who are highly knowledgeable about the effects of incarceration, specifically the effects it can have on children. The staff will be located within the community in order to help the families. Also, staff members may have to go to the prison to facilitate the training sessions; this depends on the institution's resources because some institutions already have parental training sessions. The primary duties of the staff will include contact with the families during the once/twice a month transportation to the prison; during any time the family may ask for social support; and during random, but not frequent, check-ins. It is important to have staff because they bridge the gap between the many aspects of the program, thus creating a more coherent program.

\section{Qualifications}

Unfortunately with a program like this, everyone is not going to be interested. Every parent who is incarcerated is not going to have a desire to form a bond with their child, and some children are not going to want to communicate with their incarcerated parent. This is why eligibility guidelines are imperative. The guidelines listed below are not a full account of all the qualifications for the program, but provides a basic scheme of the program.

1. Each party, parent and child, should agree to participate in the program. Depending on the age of the child, permission from the caregiver may be necessary. Although the law 
gives all rights to the caregiver once the parent is incarcerated, the child, if capable, should be able to determine if they want to see their incarcerated parent. If the caregiver wants to reject the child-parent communication, then the caregiver should have to provide a good reason to the court. A parent being incarcerated should not be sufficient enough to lose the connection of their child especially since the abundant amount of evidence shows that this loss of connection can do more harm than good.

2. The inmate must maintain good behavior within the prison. The participation of this program is a privilege that the inmate should be motivated to maintain.

3. The type of offense the inmate was convicted of will be considered. Certain offenses will automatically exclude the inmate from participation in the program. For example, inmates convicted of any offense relating to the harm of a child will not be eligible for the program. This includes, but is not limited to child abuse, sexual abuse of a minor, and possession and/or distribution of child pornography. The exclusion of these offenses is for the ultimate protection of the child. Other violent offenses such as murder, rape, and robbery, would have the opportunity to participate, but first will have to show good behavior within the institution for six months before granting participation in the program.

4. The child must be under the age of eighteen to participate in the program.

5. The incarcerated parent must participate in the parenting training session. However, due to the possible time-constraints of the caregiver, it is only highly recommended for the caregivers to participate in parental training sessions.

6. This program is for children and their incarcerated parent, but this relationship needs to be specified. The relationship does not necessarily have to be biological. If a step parent 
or non-biological father figure can prove they had a relationship with the child prior to incarceration then they will be eligible for the program.

7. Prior to the program, each incarcerated parent, child, and caregiver will go through an intensive interview to ensure they meet the qualifications; to gain information regarding the establishment of the pre-existing relationship; and to determine any other circumstances that may affect the success of the program.

8. Although all families can participate in the program, funding will depend on the financial need of the families and time flexibility—what the funding encompasses is discussed below.

\section{Solution/Program}

This pilot program is a day camp that will allow the child and parent to interact at least once a month as well as a program that provides enhanced options for the child and inmate parent to communicate. In-person visitations are important to have, but the difficulty of providing them on a frequent basis gives reason to have multiple forms of communications.

As technology advances, the different forms of communication become numerous. Many states, including Kentucky, have online services, like Jpay, that allow inmates to hold video visitations. This allows inmates to have face to face conversation with their family/friends without having to go to the prison (Loper 3). The video visitation method is much cheaper for prison institutions and families. The child can see and hear their parent which makes it more personal than a letter or email. Also, the incarcerated parent and child can interact by playing virtual games and/or reading together. However, since a large amount of families with incarcerated parents live in lower socioeconomic environments, they may not have the resources (e.g., computers) to do video visitations. In some instances, families may be able to go to the 
public library, but this is not always the case. Although the video visitation method is highly similar in benefits to the in-person visitation, this should not be seen as a substitute for in-person visitations entirely. Online visitation may be cheaper in the long run, but it is important to have in-person visitation because of the immediate personal contact that it provides.

In addition, the program can fund more common types of prison communications such as phone calls, mailing and/or emailing. Phone calls are the second most common prison communication (Loper 3). This can become costly depending on how frequently phone calls are made. The pilot program can provide a monthly budget for receiving phone calls from the incarcerated parent. This budget would depend on how much it costs to make phone calls at each institution, and it would need to be weighed with the amount of phone calls made by the incarcerated parents to the families. Phone calls are a simple form of communication. It is less personal than in-person and video visitation because they cannot see their parent, but it is more personal than writing letters and emailing because the children can hear their incarcerated parent's voice.

Mailing is the most common form of communication within prisons (Loper 3). It’s simple and less costly than visitations and phone calls. The pilot program can provide envelopes, paper, stamps and anything else needed to write a letter. The problem with letter communication is the lapse of time between when the person sends the letter and when they get a response. To illustrate, when the child sends the letter it will take a few days for the incarcerated parent to receive it and another few days for the child to receive the parent's response. This lapse of time is less personal. Furthermore, emailing is a form of communication that many prisons/jails throughout the United States have adopted for prison communication. Emailing provides a more efficient response time, and it is similar in cost to writing letters. For example, for the Jpay 
correctional service, it costs twelve dollars for sixty stamps ( 1 email= 1 stamp). Emailing is more efficient than mailing, but it is less personal than writing a letter. The child and/or caregiver's handwriting is what makes writing letters more personal than typing. The fact that there are flaws and benefits for all the different forms of communication is a reason why using various forms is important in order to maintain the connection between parent and child.

The once a month in-person visitation on Saturday will be a day camp that will last a few hours (2-4) and be supervised by correctional officers. It will allow the parent and child to have an immediate interaction by talking, playing interactive and/or educational games, and eating lunch. This in-person visitation will give the incarcerated parents the opportunity to take what they learn at the required training sessions, which are a part of the pilot program, and apply it. These training sessions will not last the entire duration of the program (i.e., the class should be 10-20 weeks depending on the institution). Incarcerated parents will attend a class a couple times a week that will teach them the most effective ways of talking and listening to their child regarding many issues including, but not limited to their incarceration, substance use, pregnancy, and academic achievement. These sessions should not seem like parenting classes in order to avoid rejection by parents or lack of participation because the incarcerated parent may get defensive if people assume they are bad parents based on the decisions they have made. That being said, it is important to understand just because a person is incarcerated does not mean they are a bad parent.

The training session should be less like a lecture and more like a seminar which allows for more discussion. In seminar settings, parents would be given the opportunity to analyze and work out the issues that they will encounter with their children. However, there are going to be instances of incarcerated parents forgoing what they learn in the training sessions and teaching 
their children the values that they were raised on. This is inevitable, but parents are going to be more likely to put what they learn into practice, especially if they are able to discuss and analyze the situation as the seminar method allows. In addition, many incarcerated parents are going to want their children to take a different path than them, so it is likely that the parents are going to apply what they learn from the training sessions.

Children will be transported to the prison to participate in the day camp. Transportation for the child will be provided, with or without the caregiver, at least one Saturday of every month for prison visitation. Although, it would be ideal to provide a higher rate of in-person visitations, the 100+ miles distance, financial cost, and time consumption would be a problem. Also, caregivers who are capable of driving the child to the prison could be reimbursed by the program for travel and other visitation costs. Finally, depending on the location of the prison and where the children live, a third option of transportation may be more efficient. The program may be able to purchase and use a van to drive a group of children to one or a more institutions.

The overall program would be a support system for the family. However, it will not provide the family with direct financial support. For example, if the caregiver is struggling financially, then the program will provide the caregiver with information for better housing, daycare, or any governmental assistance for which they may qualify, but they will not give the family money. Also, the program will offer coping support. Parental incarceration creates an emotional impact on families, and the caregivers may not know how to cope and/or explain the situation to the child (Parke and Clarke-Stewart 4-5). This can be more difficult depending on the age of the child. Younger children may have a harder time understanding and adjusting after the parent is incarcerated. This program will address this issue by providing advice and support to the caregiver regarding the best ways to explain incarceration to minors. Unlike the incarcerated 
parent, the caregiver would not have to attend a training session because of potential timeconstraints. Even though the caregivers are not required to participate in any aspect of the program, they are highly encouraged to participate in some way for the best interest of the child. For example, although the program would not provide separate training sessions for the caregiver, the caregivers can asked the program staff any questions regarding the effects of parental incarceration.

In addition, there will be another support system for children and the caregivers. This support system would be more community based. Families that are experiencing parental incarceration will be able to attend a community center once a week or once every two weeks with people that are going through similar experiences (i.e., familial incarceration). People may be more likely to talk freely about any issues relating to or resulting from the incarceration if they are surrounded with other people in similar situations. Although a large amount of families in the United States experience a family member being incarcerated, it is typically not something that is openly expressed because of the stigmatization of incarceration. This community support will hopefully stop the lack of communication regarding familial incarceration and the effects it can have. However, the community support aspect of the program would more than likely develop after the program has expanded because of the distance variability in families within the program. As mentioned in the research, most families live a 100+ miles from their incarcerated family member which can make starting a community support system more difficult (Schirmers, Nellis, and Mauer 8).

Even though it may not be as feasible to start a community support system for families experiencing incarceration, for the pilot program, families can utilize many other community support systems. Social involvement is crucial for positive youth development (Mahoney, Harris, 
and Eccles 14-5). Programs like Big Brother/Big Sister Program and/or Boys and Girls club offers the community support and mentors that children with an incarcerated parent will need to adapt to the changes. Programs like this can be found in any state and have shown undeniable results of success (i.e., socially, psychologically, academically, etc.). The staff of the pilot program can assist in helping the families find the best community support program for the child and/or caregiver.

\section{Things to Consider}

Since we typically do not associate the families of the incarcerated individual as victims, the research on the consequence of parental incarceration is not as abundant. Finding staff members informed on the topic or with experience working with these groups can be difficult. As mentioned previously, the staff are essential to the program because they bridge the gap between the families, incarcerated parent, and community. Therefore, the program would have to provide intensive training for the staff involved. This intensive training is another major financial cost of the program.

The funding of this program will need to come from donors and the state in which the institution is located. Why should they invest? For every state, the cost per inmate is significantly higher than the cost per elementary/secondary student (i.e., roughly $\$ 10,000$ vs. $\$ 30,000$ ) (Education vs Prison Costs). The long term result of this pilot program will do more good than harm, specifically saving tax payers' money by reducing incarceration and offending rates for juveniles and adults. Sometimes we have to be prepared to put money into a program that can resolve one of our biggest problems in the United States which is incarceration rates. If the program is successful and results in a reduction in the number of individuals incarcerated in a 
state, the funds previously used to support the incarceration could be re-invested in this and other similar community based programs.

A confounding factor of the program is the length of sentence for the incarcerated parent. If a parent is incarcerated for $20+$ years then would maintaining the relationship between parent and child be worth it? This is difficult to determine; especially since there is not much research, if any, regarding the relationship between the length of time of the incarcerated parent and the effects these various lengths of times can have on the children. We could assume that maintaining the connection between parent and child will be beneficial no matter how long the parent is incarcerated, but without further research we cannot be certain.

\section{CONCLUSION}

It becomes easy to overlook or disregard the negative effects on a family once a parent is incarcerated. We may think this is the price the offender pays for their crime- why should we do them a favor by helping them keep the connection with their families, specifically their children? But we are not solely doing the inmates and their families a favor. As discussed, disregarding this connection has greater effects that impact society as a whole. So, we should not see the movement of maintaining the familial connection as doing a favor for the offender, but for ourselves and our society. The pilot program is more than maintaining the connection between parent and child; it is the start of reevaluating our justice system. Hopefully, we can stop portraying the "victims" of a crime as only being the people involved directly in the crime and start to include the children, families, and citizens of the community. This realization of a greater impact will hopefully inspire people to take a bigger role in reducing the offending and incarceration rates of the United States. 
Works Cited

Arditti, Joyce A. "Locked Doors And Glass Walls: Family Visiting At A Local Jail." Journal Of Loss \& Trauma 8.2 (2003): 115-138. Academic Search Complete. Web. 15 Feb. 2015.

"Assigning Inmates to Prison." North Carolina Department of Public Safety, 2012. Web. 26 Feb. 2015.

Beckmeyer, Jonathon J., and Joyce A. Arditti. "Implications Of In-Person Visits For Incarcerated Parents’ Family Relationships And Parenting Experience." Journal Of Offender Rehabilitation 53.2 (2014): 129-151. Academic Search Premier. Web. 13 Apr. 2014.

Carson, Ann E. "Prisoners in 2013." Bureau of Justice Statistics (2014): 1-32. U.S. Department of Justice, Sept. 2014. Web. 14 Jan. 2015.

Chang, Cindy. "States of Incarceration: The Global Context." Prison Policy Initiative. (2012): 12. Web. 15 Feb. 2015.

Choi, Namok. "A Structural Model Of Parent Involvement With Demographic And Academic Variables." Psychology In The Schools 52.2 (2015): 154-167. Academic Search Complete. Web. 24 Feb. 2015.

Christian, Steve. “Children of Incarcerated Parents.” National Conference of State Legislatures (2009): 1-18. Web. Nov. 2014. 
Crain, Christina Melton. "Children Of Offenders And The Cycle Of Intergenerational Incarceration." Corrections Today 70.5 (2008): 64-67. Academic Search Premier. Web. 13 Apr. 2014.

Dodson, Lisa, Randy Albelda, Diana Coronado, Marya Mtshali. “How Youth Are Put At Risk by Parents’ Low-Wage Jobs.” Center for Social Policy Publications (2012): 1-29. Web. 2 Feb. 2015.

Domer, Ryan A. "Increasing Awareness of Stigmatization: Advocating the Role of Occupational Therapy.” The University of Toledo Digital Repository (2012): 1-108. Web. 1 Mar. 2015.

"Education vs Prison Costs." CNNMoney. Cable News Network, 2015. Web. 15 Feb. 2015.

“Educational Attainment, Employment and Incarceration.” U.S. Washington State (2012): 1-3. Web. 10 Feb. 2015.

El Nokali, Nermeen E., Heather J. Bachman, and Elizabeth Votruba-Drzal. "Parent Involvement And Children’s Academic And Social Development In Elementary School." Child Development 81.3 (2010): 988-1005. Academic Search Complete. Web. 15 Feb. 2015.

Farlee, Julee P. "Family Socioeconomic Hardship and Adolescent Academic and Substance Use Outcomes: The Mediating Roles of Parental Monitoring and Self-Regulation." Virginia Polytechnic Institute and State University (2011): 1-34. Web. 16 Jan. 2015. 
"Girl Scouts Beyond Bars." Girl Scouts of America. 2015. Web. 16 Jan. 2015.

Glaze, Lauren E., and Laura M. Maruschak. Parents in Prison and Their Minor Children. Washington,DC: U.S. Dept. of Justice, Office of Justice Programs, Bureau of Justice Statistics, 2008. 30 Mar. 2010. Web.

Haveman, Robert, and Timothy Smeeding. "The Role Of Higher Education In Social Mobility." Future Of Children 16.2 (2006): 125-150. Academic Search Complete. Web. 27 Feb. 2015.

Henrichson, Christian, and Ruth Delaney. "The Price of Prisons: What Incarceration Costs Taxpayers.” Vera Institute of Justice: Making Justice Systems Fairer and More Effective through Research and Innovation." (2012): 1-28. Web. 12 Feb. 2015.

James, Doris J. "Profile of Jail Inmates, 2002." Bureau of Justice Statistics (BJS) (2004): 1-12. U.S. Department of Justice. Web. Oct. 2014.

La Vigne, Nancy G., Elizabeth Davies, and Diana Brazzell. "Broken Bonds." Understanding and Addressing the Needs of Children with Incarcerated Parents (2008): 1-17. Urban Institute Justice Policy Center. Web. Jan. 2015.

Light, Roy, and Bryony Campbell. "Prisoners' Families: Still Forgotten Victims?." Journal Of Social Welfare \& Family Law 28.3/4 (2006): 297-308. Academic Search Complete. Web. 28 Feb. 2015. 
Loper, A. B., \& Coleman, E. S. (2014). “Video Visitation for Inmates: Thinking Outside of the Tiny Box.” Corrections Today, 76(2), 54-59.

Madon, Stephanie, et al. "Self-Fulfilling Prophecies: Mechanisms, Power, And Links To Social Problems." Social \& Personality Psychology Compass 5.8 (2011): 578-590. Academic Search Complete. Web. 24 Feb. 2015.

Mahoney, Joseph L., Angel L. Harris, and Jacquelynne S. Eccles. “Organized Activity Participation, Positive Youth Development, and the Over-Scheduling Hypothesis.” Social Policy Report: Giving Child and Youth Development Knowledge Away (2006): 1-32. Web. 2 Feb. 2015.

Makariev, Drika Weller, and Phillip R. Shaver. "Attachment, Parental Incarceration And Possibilities For Intervention: An Overview." Attachment \& Human Development 12.4 (2010): 311-331. Academic Search Complete. Web. 15 Feb. 2015.

Miller, Alison, and Shirley Cochran. "Motherly Intercession." Prevention Research Center of Michigan. National Institutes of Health, Michigan Institute for Clinical \& Health Research (MICHR), 2012. Web. 16 Feb. 2015.

Miller, Keva. "The Impact Of Parental Incarceration On Children: An Emerging Need For Effective Interventions." Child \& Adolescent Social Work Journal 23.4 (2006): 47286. Academic Search Complete. Web. 14 Feb. 2015.

“Missouri 4-H Life (Living Interactive Family Education)” 4-H National Headquarters (2010): 
1-11). Web. 10 Feb 2015.

Morgan, Hani. "Poverty-Stricken Schools: What We Can Learn From The Rest Of The World And From Successful Schools In Economically Disadvantaged Areas In The Us." Education 133.2 (2012): 291-97. Academic Search Complete. Web. 16 Feb. 2015

Parke, Ross D., and Alison K. Clarke-Stewart. "Effects of Parental Incarceration on Young Children." The Urban Institute (2002): 1-24. U.S. Department of Health and Human Services, Web. 16 Feb. 2015.

Sander, Janay B., Jill D. Sharkey, Amber N. Groomes, Lauren Krumholz, Kimberly Walker, and Julie Y. Hsu. "Social Justice and Juvenile Offenders: Examples of Fairness, Respect, and Access in Education Settings." Journal of Educational and Psychological Consultation 21.4 (2011): 309-37. 11 Nov. 2011. Web. 09 Nov. 2014.

Steinberg, Laurence, et al. "Age Differences In Sensation Seeking And Impulsivity As Indexed By Behavior And Self-Report: Evidence For A Dual Systems Model." Developmental Psychology 44.6 (2008): 1764-1778. Academic Search Complete. Web. 14 Nov. 2014.

Schirmer, Sarah, Ashley Nellis, Marc Mauer. "Incarcerated Parents and Their Children Trends 1991-2007." The Sentencing Project. (2009): 1-11. Web. 5 Jan 2015.

"The Elementary and Secondary Education Act (ESEA)." National Education Association, 2015. Web. 26 Feb. 2015. 
Tuerk, Elena Hontoria, and Ann Booker Loper. "Contact Between Incarcerated Mothers And Their Children: Assessing Parenting Stress." Journal Of Offender Rehabilitation 43.1 (2006): 23-43. Academic Search Complete. Web. 15 Feb. 2015.

Travis, R., \& Leech, T. J. “Empowerment-Based Positive Youth Development: A New Understanding of Healthy Development for African American Youth.” Journal Of Research On Adolescence (Wiley-Blackwell), 24(1) (2014): 93-116. Web. 15 Feb. 2015.

Turney, Kristin. "Stress Proliferation Across Generations? Examining The Relationship Between Parental Incarceration And Childhood Health." Journal Of Health \& Social Behavior 55.3 (2014): 302-19. Academic Search Complete. Web. 14 Feb. 2015.

Wun, Connie. "The Anti-Black Order Of No Child Left Behind: Using Lacanian Psychoanalysis And Critical Race Theory To Examine NCLB." Educational Philosophy \& Theory 46.5 (2014): 462-74. Academic Search Complete. Web. 11 July 2014.

Young, Diane S., and Carrie Jefferson Smith. "When Moms Are Incarcerated: The Needs Of Children, Mothers, And Caregivers."Families In Society 81.2 (2000): 130-41. Academic Search Complete. Web. 15 Feb. 2015. 